\title{
Otters in Morocco
}

\author{
Sheila M. Macdonald and Christopher F. Mason
}

That otter numbers have declined in northern Europe is well known and the Vincent Wildlife Trust is attempting to discover how far this is also true in the southern part the otter's range. Healthy populations have been found in Portugal, Greece and northern Tunisia but declines have occurred in other Mediterranean countries. Here the authors describe the results of a survey in Morocco.

In view of the precarious state of the European otter, Lutra lutra in much of northern Europe, an attempt is being made to establish its distribution and status in the south of its range. As part of this study a survey of Morocco was undertaken.

\section{The survey}

The survey was carried out between 8 and 21 April 1983 and, because of shortage of time, was confined to an area west and north of the Haut Atlas. Sites were chosen to give maximum coverage in the time available. At each site a minimum of $200 \mathrm{~m}$ of river bank was searched for signs of otters (spraints or footprints) and the species was considered absent from a site if no signs were found within $600 \mathrm{~m}$. Notes were made on the habitat at each site.

\section{Results}

A total of 78 sites (see Figure 1) was visited and signs of otters were found at 36 (46 per cent). A further 12 sites, indicated as permanently flowing water on current 1:1,400,000 maps, were found to be dry. In the lowlands a few otters were located in the plains of the Oued Tensift and $\mathrm{O}$. Rbia and a remnant population remains around the tidal lagoon of Merja Zerga but 75 per cent of all positive sites were in foothills. Of the 40 upland sites visited, otters were found at 67.5 per cent with 82 per cent of the 22 sites in the Moyen Atlas proving positive. There was no relationship between river width and the presence of otters.

The habitat was assessed at each site in terms of available daytime cover for otters. At 14 (39 per cent) of the positive sites the habitat was con-

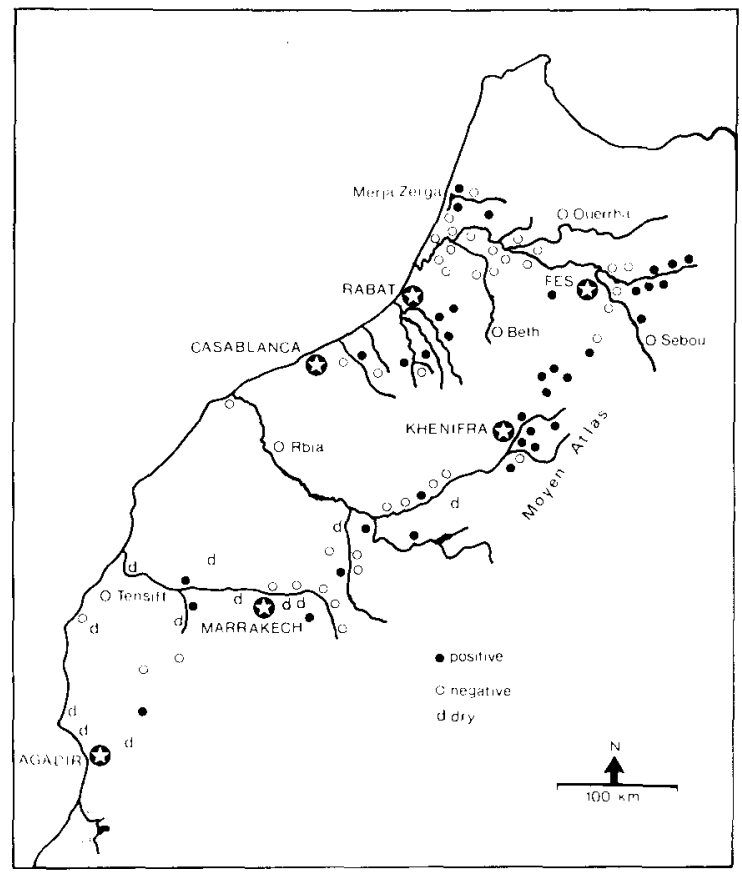

Figure 1. The study area in Morocco showing sites visited. 


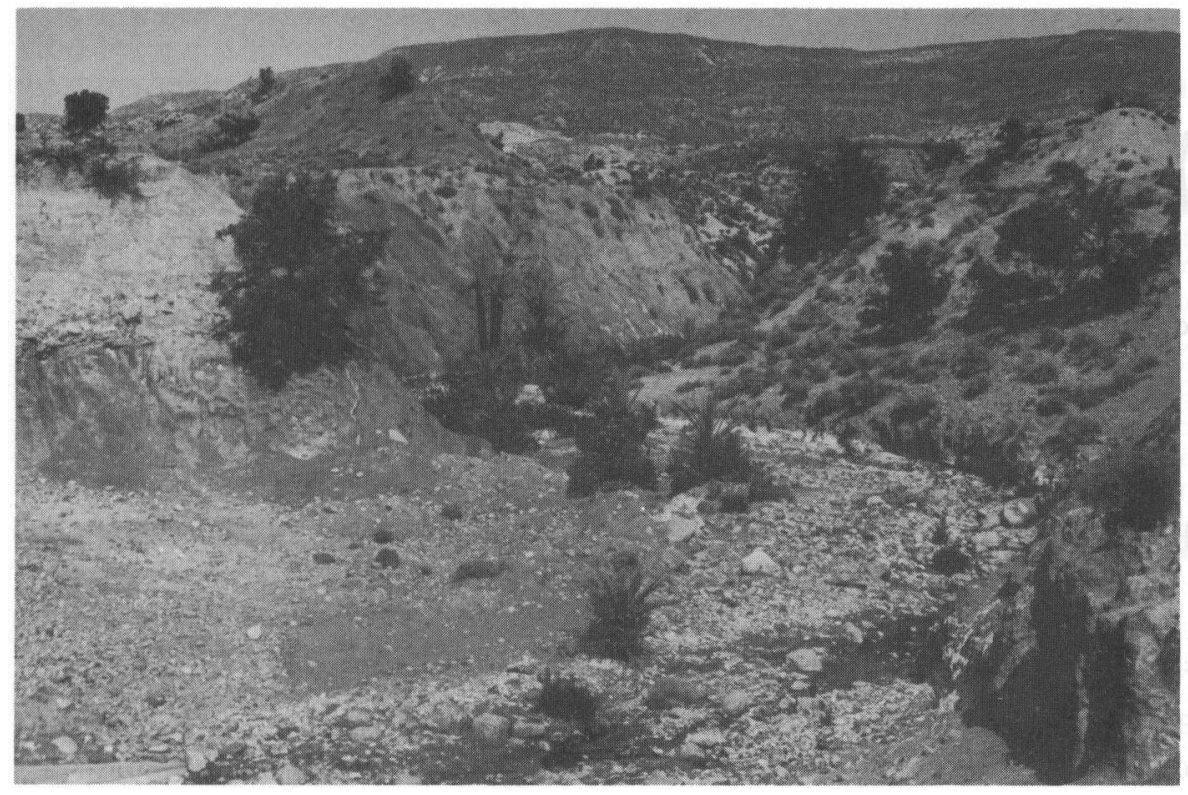

Small stream northeast of Agadir, the most southerly of the positive sites. Rock crevices offered shelter for otters (Sheila Macdonald).

sidered as ideal and shelter could be found in holes in banks and in dense riparian vegetation. Growths of oleander Nerium oleander, bramble Rubus sp. and rose Rosa sp. were often impenetrable while willow Salix sp., tamarisk Tamarix sp. and ash Fraxinus sp. were also common. Habitat was of moderate value at 25 per cent of positive sites but at 36 per cent there was very little obvious cover. These poor sites included most of those to the east of Fes and east of Rabat but these regions also contained inaccessible wooded hills where otters might find shelter. By contrast, all but two of the sites around Khenifra offered ideal habitat with rivers flowing off well-vegetated hills.

Apart from Merja Zerga, the region from Fes to north of Rabat produced no signs of otters. At all but two sites there was no bankside cover. The area comprises a lowland plain with intensive cereal production and, as in the plain of the $\mathrm{O}$. Rbia, it was clear that herbicide, and probably pesticide, application had been extensive.

Throughout the whole area surveyed only eight sites were visited where both habitat and food supply appeared adequate but where no signs of otters were found.

Rivers were everywhere intensively used by people for washing, collecting water and watering 158 livestock but only three sites were visibly polluted.

\section{Discussion}

In the south of the otter's range it is now known that healthy populations still remain in Portugal and Greece (Macdonald and Mason, 1982a,b), that declines have occurred in Spain and Yugoslavia (Elliot, 1983; Liles and Jenkins, in prep.) and that the otter in Italy is endangered (Macdonald and Mason, 1983a). In Tunisia the species is still common in the extreme north where many rivers are well-vegetated with $N$. oleander (see Macdonald and Mason, 1983b).

In the survey of Morocco the main populations were found in the low Moyen Atlas although bankside habitat was not always ideal. At higher altitudes, montane streams offered little food for the animals. Rivers with most vegetation (e.g. those around Khenifra) flowed from tree- and scrub-covered hills but in many other areas overgrazing has denuded hillsides.

Otter distribution in Morocco is clearly limited by lack of water; there are very few rivers between Casablanca and Agadir or inland to Marrakech. In addition, since the country became independent in 1955, 30 dams have been built (Abouzaid and Hajji, 1982) and outflow catchments were frequently found to be dry.

Oryx Vol 18 No 3 
Drying river in semidesert east of

Marrakech. Despite the lack of flowing water or bankside vegetation this site was used by otters (Sheila Macdonald).

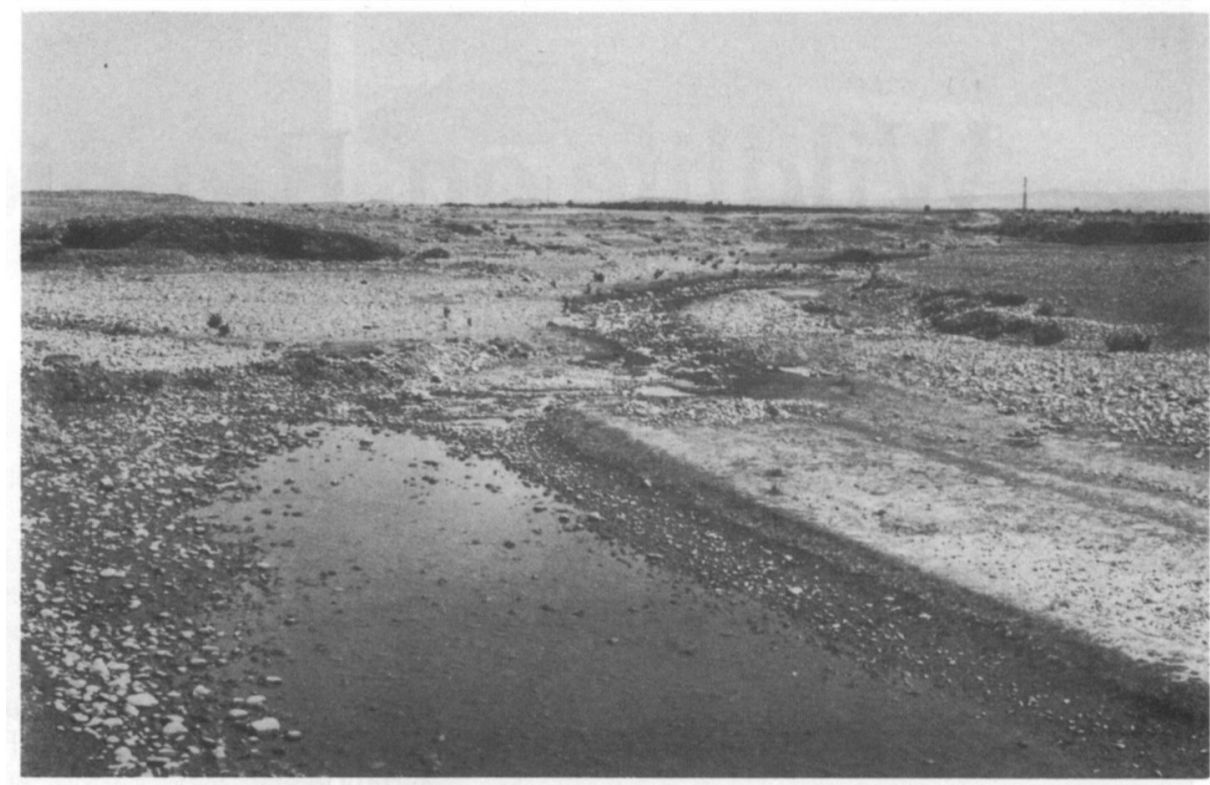

Apart from livestock and citrus orchards, the agriculture is largely arable with intensive cereal production. In Greece, with similar agricultural plains, otters are common in the irrigation ditches (Macdonald and Mason, 1982b) but in Morocco the water is frequently supplied in raised concrete channels. Very few otters were found in the lowland areas. As in Spain and Yugoslavia (Elliot, 1983; Liles and Jenkins, in prep.), where populations have become fragmented, more signs were found in the uplands. A number of recent Moroccan observations of otters provided by $\mathrm{S}$. Aulagnier (in litt.) also fall mainly within the upland areas. In Morocco a small population still remains centred on Merja Zerga, which is listed as a wetland site of international importance under the Ramsar Convention. The inflow channels to the lagoon do not provide adequate cover for otters but, while emergent vegetation in the Merja is heavily grazed, the variety of fish species (Morgan, 1982), and its relative inaccessibility make it suitable for the animals.

As in Tunisia, Moroccan rivers are in constant use by people and livestock but, in both countries, there is little visible water pollution. In Tunisia otter distribution is confined to the north where the majority of positive sites provided ideal cover. Further south, where rivers run through semi- desert, there is little bankside vegetation. In Morocco otters are more limited by a lack of water and intensive arable production while fewer rivers offer suitable cover. Bankside scrub appeared to be cut for fuel in Morocco but there was little evidence of this in Tunisia.

\section{Acknowledgment}

We would like to thank Dr S. Aulagnier of the Université Sidi Ben Abdellah, Meknes, for additional information on Morocco.

\section{References}

Abouzaid, H. and Hajji, A. 1982. L'eau potable au Maroc. Aqua, 2, 13-18.

Elliot, K.M. 1983. The otter (Lutra lutra L.) in Spain. Mammal Rev. 13, 25-34.

Macdonald, S.M. and Mason, C.F. 1982a. The otter Lutra lutra in central Portugal. Biol. Conserv. 2, 207-215.

Macdonald, S.M. and Mason, C.F. 1982b. Otters in Greece. Oryx. XVI, 240-244.

Macdonald, S.M. and Mason, C.F. 1983a. The otter (Lutra lutra) in southern Italy. Biol. Conserv. 25, 95-101.

Macdonald, S.M. and Mason, C.F. 1983b. The otter (Lutra lutra) in Tunisia. Mammal Rev. 13,35-37.

Morgan, N.C. 1982. An ecological survey of standing waters in north west Africa: III. Site descriptions for Morocco. Biol. Conserv. 24, 161-182.

Sheila M. Macdonald, The Vincent Wildlife Trust. Baltic Exchange Buildings, 21 Bury Street, London EC 3A 5AU, UK. Christopher F. Mason, Department of Biology. University of Essex, Colchester, Essex, UK. 